\title{
Büyük Verinin Sağlık Hizmetleri Kalitesindeki Rolï
}

\author{
The Role of Big Data in Healthcare Quality
}

\section{Selma Altındiş}

Sakarya Üniversitesi İşletme Fakültesi Sağlık Yönetimi Bölümü

Yazıșma Adresi / Correspondence: Selma Altındiş

Sakarya Üniversitesi İşletme Fakültesi Sağılk Yönetimi Bölümü. Serdivan/SAKARYA

T: +90 5056676710 E-mail: altindis@sakarya.edu.tr

Geliş Tarihi / Received : 11.05.2018 Kabul Tarihi / Accepted : 25.05.2018

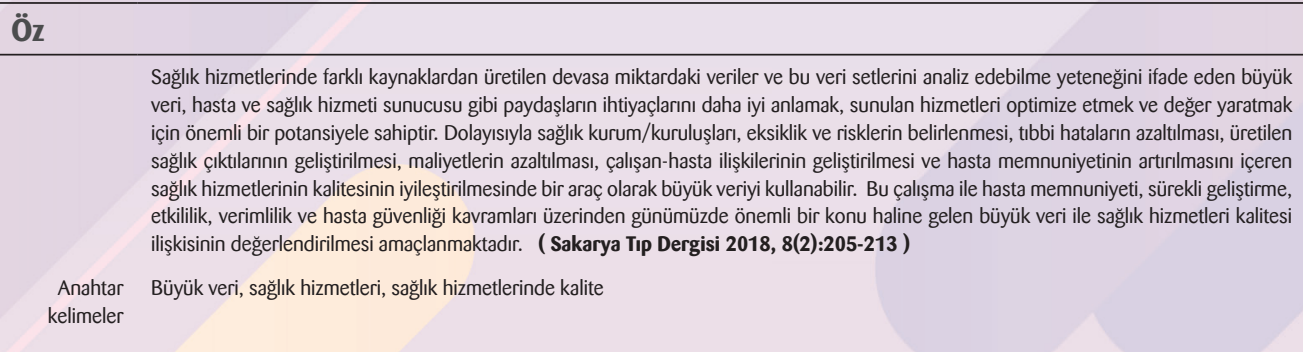

Big data that is a term that describes a huge amount of data produced from different sources and expressing the ability to analyze them has an important potential to better understand the needs of parties such as patients and health care providers, to optimize services and to create value in health care services. Therefore, big data can use as a vehicle by health institutions/organizations the quality of health care in general including determination of deficiencies and risks, reduction of medical errors, development of health outputs, reduction of costs, improvement of employee-patient relations and increasing patient satisfaction. This study is aims to evaluate the relationship between big data and the quality of health care services through the concepts of patient satisfaction, continuous improvement, effectiveness, productivity and patient safety. ( Sakarya Med J, 2018, 8(2):205-213 ).

Keywords Big data, healthcare services, quality in healthcare 
Sakarya Tip Dergisi 2018;8(2):205-213

\section{Büyük Veri Kavramı}

Büyük veri "tipik veritabanı yazııım araçları ile yakalama, depolama, yönetme ve analiz etme yeteneğinin üstünde bir boyuta sahip olan veri kümeleri" olarak tanımlanır. ${ }^{1}$ Ayrıca "büyük veriler, yüksek hacim, hız ve çeşitlilik ile karakterize edilen bilgiyi” temsil eder. ${ }^{2}$ Bu tanımda büyük verileri ifade eden ve vurgulanması gereken kelime "bilgi varlıkları" dır. Çünkü "bilgi varlıkları" nın açıkça tanımlanabilen ve uygulama alanına bağımlı olmayan bir kavram olduğu belirtilmektedir. Bu varlıklar, değer dönüşümü için belirli teknoloji ve analitik yöntemleri gerektirir. ${ }^{2}$ Büyük veri ile kullanılan analitik teknikler arasında veri madenciliği, görselleştirme, istatistiksel analiz ve makine öğrenimi yer alır. ${ }^{3}$ Büyük veriler, ya algoritmalar geliştirir ya da bu algoritmaların çalışması için gereken ham maddeyi sağlar. ${ }^{1}$

Bu değere ulaşmak üzere kuruluşlar bugün, hem kamu veri kaynakları hem de sosyal medya ve açık veriler gibi özel kaynaklardan büyük miktarda veri topluyorlar., ${ }^{4,5}$ Bu devasa boyuttaki veriler, eğer doğru analiz metotları ile yorumlanabilirlerse doğru stratejik karar verme, riskleri azaltma, istenen kaliteyi sağlama ve inovasyon için kurumlara önemli fırsatlar sunabilir. Çünkü gelişmiş analizler, karar vermeyi önemli ölçüde geliştirebilir, riskleri en aza indirebilir ve gizli kalacak olan değerli bilgileri ortaya çıkarabilir. ${ }^{1}$

\section{Sağlık Hizmetlerinde Büyük Veri}

Sağlık hizmetleri bağlamında büyük veri, büyük miktardaki elektronik sağlık verilerini verimli bir şekilde oluşturmak, depolamak, işlemek, analiz etmek için kullanılan araçlar, teknolojiler, yöntemler ve prosedürler topluluğu olarak tanımlanabilir. ${ }^{6}$ Büyük veri, sağlık verilerini işleyebilme, bakım noktasında klinisyenlere anlık bilgi verme ve bazen de ondan şaşıtıcı sonuç çıkarma yeteneği anlamında kullanılmaktadır. ${ }^{7}$

Sağlık sektörü, verilerin yoğun bir şekilde üretildiği bir sektördür. Klinik, genetik, davranışsal, çevresel, finansal ve operasyonel alanlardan toplanan sağlık verileri her geçen gün artmaktadır. ${ }^{4,5}$ SağIık hizmetlerinde farklı biçimlerde ve birçok kaynaktan üretilen bu veriler: Hastalara ait demografik veriler, tıbbi geçmişleri, aktif tıbbi problemleri, aşlar, alerjiler, ilaçlar, vital bulgular, laboratuar ve radyoloji testlerinden elde edilen sonuçlar, patoloji raporları, sağlık hizmeti sunucuları tarafından hazırlanan ilerleme notları, sağık talepleri ve fatura kayıtları gibi idari ve mali belgeler, elektronik tıbbi kayıtlar (EMR), hasta kayıtları, uzaktan algılayıcılar, giyilebilir cihazlar, akıllı sayaçlar ve sensörlerden gelen veriler, yaşamsal bulgu cihazlarından elde edilen veriler, kişilerin parmak izleri, retina taramaları, Facebook, Twitter ve diğer sosyal medya platformları ile kullanıcıların konumlarını, sağıık davranışlarını, duygularını ve sosyal etkileşimlerini içeren veriler, bireylerin günlük hayatlarındaki egzersiz düzeylerini gösteren adım sayıları, kilo değişimleri, beslenme şekilleri, tükettikleri gıdalar, yararlı/zararlı alışkanlıkları vs. gibi yapılandııımış ve yapılandııılmamış verilerdir. ${ }^{4,6,8-13}$ Ancak bu verilerden kısa sürede bir değer yaratmak bazı gelişmiş analiz tekniklerini ya da teknolojilerini gerektirir. Veri setlerini analiz edebilme yeteneğini de ifade eden büyük veri, paydaş (ör. hasta, klinisyen) ihtiyaçlarını daha iyi anlamak, mevcut ürünleri ve hizmetleri optimize etmek ve değer yaratmak için önemli bir potansiyele sahiptir. ${ }^{4}$

Sağlık hizmetlerinde farklı kaynaklardan üretilen ve devasa boyutları kapsayan büyük veri olarak tanımlanan veriler; klinik uygulama ve araştırma, hastalık sürveyansı ve toplum sağlığı yönetimi, sağık eğitimi ve öğrenimi, sağılı hizmetleri sunum kalitesinin ve verimliliğinin arttırılması, hasta- 
Iıkların erken evrelerinde saptanması, klinik karar desteği alma, ilaç geliştirme ve pazarlama gibi alanlarda kullanılabilir. ${ }^{10,11,14}$ Ağırıklı onkoloji olmak üzere kardiyoloji, nöroloji ve toplum sağlığı araştırmalarında da büyük verilerden faydalanılabileceği öngörülmektedir. ${ }^{14}$ Büyük veri araştırma merkezleri ile halk sağlığı sürveyansı ve gıda kaynaklı hastalık eğilimlerin belirlenmesi mümkün olabilir. Elde edilen bu veriler, hükümetlere uygun müdahale politikalarını seçmede yardımcı olmak için kullanılabilir. ${ }^{14}$

Sonuç olarak sağlıkta üretilen veri miktarının oldukça geniş hacimlere ulaştı̆̆ı', bu geniş hacim, çeşitlilik ve veri hızıyla başa çıkmak4 ya da bu verilerden potansiyel olarak sınırsız olasılıkları ortaya çıkaran ve değer yaratan bilgileri elde etmek, büyük veri uygulamalarılla sağlanabilir. Değer yaratan bilgilerden biri de hastalara sunulan sağlık hizmetlerinin kalitesini artırabilmesine ilişkindir. ${ }^{9}$

\section{Sağlık Bakım Kalitesinde Büyük Veri kullanımı}

iletişim ve bilgisayar teknolojilerinin gelişimi, toplumda artan internet ve sosyal medyanın kullanımı, tüm sektörlerin yanı sıra sağlık sektöründe de önemli değişimleri beraberinde getirmiştir. Bu değişim sağık hizmetlerinin kalitesini geliştirmek ve maliyetlerini düşürmek için sağlık kuruluşlarını, dijital bilgilere dayanan veri ve analizine yöneltmektedir.

Ulusal Kalite Forumu (NQF) tarafından hazırlanan raporda da sağılk endüstrisinin elinde bol miktarda büyük veri olduğu, bu zengin ham veriden anlamlı ve uygulanabilir bilgiler elde edebilme yeteneğinin, hasta sonuçlarını iyileştirme ve kalite için bir anahtar olabileceği belirtilmektedir ${ }^{15,16}$. O halde kurumlar bu yeteneği kazanma ve geliştirmeye odaklanmalıdır. Çünkü veri odaklı sağılk kurumlarının merkezinde hasta, personel ve nüfus profilleri yanı sıra finansal, klinik ve operasyonel süreçlere ilişkin kurum içi ve dışından geniş bir çeşitlilikte üretilen büyük hacimli verileri analiz edebilme yeteneği bulunmaktadır. ${ }^{17}$ Bu veri ve analiz yeteneği, etkin ve verimli sağılık hizmetleri sunumunda önemli katkılar sunabilecek potansiyele sahiptir.

Sağlık hizmetlerinde istenen kalite düzeyine erişim için toplam kalite ilkelerinin dikkate alınması gereklidir. Toplam kalite temel ilkeleri içinde hasta memnuniyeti, sürekli iyileşme ve geliştirme, müşteri odaklılık, katılım, performansının ölçülmesi, hataların önlenmesi, ölçüm ve denetim yer alır. ${ }^{18-20}$ Ayrıca Institute of Medicine (IOM) (2001) yüksek kaliteli bakımın 6 bileşeninden bahseder. Bunlar: etkili, güvenli, zamanında, verimli, adil ve hasta odaklı olmaktır. Hasta odaklı olmak ise, hastaların değerlerine, tercihlerine ve ifade edilen ihtiyaçlarına saygılı olmak, bakımın koordinasyonu ve entegrasyonunu sağlamak, hasta ile iyi bir iletişim kurmak ve sürece hasta yakınlarının katılımını gerektirir. ${ }^{21,22}$

\section{Hasta Memnuniyeti ve Büyük Veri}

Hizmetlerin üretiminin temel nedeni olan hastaların beklentilerini karşılamak ve sunulan hizmetleri iyileştirmek, hizmet kalitesinin temel esaslarındandır. ${ }^{23,24}$ Çünkü hasta memnuniyeti, beklentilerin karşılanma düzeyini gösteren ve bakım kalitesinin göstergesi olan önemli bir ölçüttür. ${ }^{25}$ Büyük veri setlerinin daha iyi analizi sayesinde paydaşların (örneğin hasta, klinisyen gibi) ihtiyaçları, daha iyi anlaşılabilir, mevcut ürünleri ve hizmetleri optimize etmek ve yeni değer yaratacak önerileri geliştirmek mümkün olabilir. ${ }^{4}$ Özellikle bilgisayar teknolojisindeki ilerlemeler (büyük veri teknolojileri gibi), hasta izleme sistemleri ve elektronik sağlık kayıt sistemlerinden hasta verilerinin elektronik ortamda hızlı bir şekilde toplanmasına olanak sağlamıştır. ${ }^{26}$ Birçok sağlık hizmeti sunan kurumun
Sakarya Tip Dergisi

2018;8(2):205-213

ALTINDiş

Sağllkta Kalited

Büyük Veri 
Sakarya Tip Dergisi 2018;8(2):205-213 hasta sonuçlarını iyileștirmesi, maliyetleri düşürmesi ve gelirlerini artırması, bu verileri kullanabilme kabiliyetlerine bağlıdır. Büyük veri setlerini yakalama, entegre etme ve sorgulama yeteneği ölçüsünde işletmeler, klinik etkinlik, kalite ve sonuçları iyileştirme fırsatı yakalayacaktır. ${ }^{27}$

\section{Sürekli Gelişme/Iyileştirme ve Büyük Veri}

Kalite sürekli gelişmeyi gerektirir. Çünkü sağlık hizmetlerinde kalite, durağan bir konum değil, sunulan tüm hizmetlerde en iyi sonuçlara ulaşmak üzere sürekli çaba göstermeyi, tüm faaliyetlerini ve politikalarını bu amaca erişmek için geliştirmeyi amaçlayan dinamik bir süreçtir. ${ }^{23,25}$

Iyileştirmenin ilk aşaması mevcut durumun bilinmesidir. Çünkü iyileştirme, mevcut durum hakkında verilerin toplanıp, iyileştirme alanlarının tespitiyle gerçekleşebilir. ${ }^{23}$ Sürekli iyileştirme, sağılı hizmetlerinde kalitenin temel ilkelerinden biridir28 ve sistem yaklaşımını gerektirir. Bu yaklaşım ise, bir hastanın bakımına katılan birçok klinisyen ve sağık çalışanını, modern teşhis ve tedavilerin karmaşıklğını, çeşitliliğini, sağılı bakımı sunan farklı kurumları (hastaneler, ayaktan tedavi klinikleri, evde bakım hizmetleri ve diğer kurumlar) ve sağlığın farklı belirleyicileri gibi birçok unsurunu birden dikkate alır. Kurumlar sürdürülen iyileşme ve gelişimler için kendi potansiyellerini belirleyen, fırsatları tanımlayan, ilerlemeyi ölçen ve kullanıcılara hangi verilerin işe yaradığını anlamasına yardımcı olan sağlığın farkı belirleyicilerinden gelen çok çeşitli veri türünün analizine ihtiyaç duyar. ${ }^{15}$ Bu verilerin analizleri, büyük veri analiz yöntemleri ile sunulabilir.

\section{Performans ölçümü ve büyük veri}

Sağlık kuruluşları, ölçüm yapamadıklarını geliştiremezler. ${ }^{23,29-31}$ Ölçümün amacı, bilgi toplamaktır. Sağlık kuruluşları, hasta bakımı ve destek işlevlerinin kaliteleri hakkında bilgi toplamak için performanslarını izlemektedirler. Bu bilgileri performansı anlamak ve performansın zaman içinde nasıl değiştiğini veya geliştiğini görmek amacıyla kullanmaktadırlar. ${ }^{23} \mathrm{O}$ halde kuruluşlar, gerek performanslarını iyileştirmek gerekse de uzun vadeli başarılarını sağlamak için sahip olduğu verileri şu alanlarda kullanabilirler: ${ }^{17}$

- Gerçek maliyet ve sonuçların daha iyi anlaşılmasını sağlamak

- Gelişmelerden en fazla yararlanacakları alanları belirlemek

- Zamanla performansı sıkı bir şekilde takip etmek

Yukarıdakilerin yanı sıra kestirilebilir risk değerlendirmesi, klinik karar destek ve kaynak yönetimi gibi kalite ve performans iyileştirmelerinde nicel ve nitel verilerin analizleri sistematik olarak kullanılabilir. Bu verilerin analizleri, büyük veri analiz yöntemlerinden biri olan görsel analitik ile kolaylıkla sağlanabilir. Çünkü görsel analitik, etkileşimli görsel arayüzlerle kolaylaştııılmış analitik akıl yürütme bilimidir ve büyük verileri içeren bilişsel etkinliklerin performansını kolaylaştırabilir. ${ }^{26}$

\section{Maliyet Etkinliği ve Büyük Veri}

Kalitede maliyet etkinliği, istenilen sağlık hizmeti sonucunu elde etmek için gerekli minimum harcama miktarı, zaman ve diğer unsurları dikkate alır. ${ }^{23}$ Sağlık sisteminin bakım ve maliyet etkinliğini artırmak için hastane veya klinik verilerinden yüksek riskli ya da yüksek maliyetli hastalar ve süreçlerin belirlenmesi, büyük veri analizi ile kısa sürede ve kolaylıkla yapılabilir. ${ }^{32}$ Örneğin hastaneler belirli bir hastanın tedavisinin aciliyet derecesini belirlemek için büyük veriyi kullanabilir. Büyük veri hastanelerin, bir hastanın ihtiyaçlarını karşılamak için doğru miktarda personel ve teçhizatın tahsisine ilişkin plan yapmalarına yardımcı olabilir. Bu alanda büyük veri teknolojilerini ve analizle- 
rini kullanarak hastaneler, zaman, kaynak veya para tasarrufu sağlayabilir ${ }^{33}$. Çünkü sağlık kalitesi ve verimliliğini artırmak üzere değer üreten bilgilerin elde edilmesi, büyük verinin sunduğu imkanlarla kolaylıkla sağlanabilir. ${ }^{4}$ Ayrıca özellikle ko-morbiditeye (eşzamanlı birden çok hastalı̆a) sahip olan ve yüksek maliyetlere sahip kompleks hastalarda gelişmiş bakım koordinasyonu ve yönetimi sağlamak, bakım kalitesini artııırken maliyetleri de düşürebilir. Eşzamanlı birden çok hastalığa sahip olan bu hastalarda bakım ve maliyetlerini öngörmek ve yönetmek için çeşitli veri türlerini kullanan tahminsel algoritmalar dikkate alınabilir. ${ }^{34}$

\section{Etkililik ve Büyük Veri}

IOM’a göre yüksek kaliteli bakımın bileşenlerinden biride sunulan hizmetlerin etkili olmasıdır. ${ }^{22}$ Etkililik, bilimsel bilgiye ve kanıt temelli yönergelere dayanan hizmetler sunmaktır. ${ }^{35}$ Yani tanı ya da tedaviye ilişkin kararlarda bilimsel kanıtlara dayandırılarak en iyi sonucu verecek şekilde karar verilmesidir. ${ }^{22}$

Günümüzde sağık hizmeti sunan kurumlarının klinik etkinliği, kaliteyi ve sonuçları iyileştirme gibi hedefleri gerçekleştirirken, büyük bilgi setlerini yakalama, entegre etme ve sorgulama yeteneklerinin temel alınacağı belirtilmektedir. ${ }^{27}$ Çünkü kurumların bilgi kullanım kabiliyetleri, klinik etkinlik, kalite ve çıktıları iyileştirmek için uygulanacak en etkili ve uygun maliyetli tedavileri tanımlama imkanı sunar. Böylece hasta özelliklerini, tedavilerin maliyetini ve sonuçlarını analiz etmek mümkün olabilir. Ayrıca aynı sonucu elde etmek için bu yetenekle, hizmet sağlayıcıların davranışlarının da analiz edilmesi ve uygun araçlar önerilmesi söz konusu olabilir. ${ }^{27}$ Yüksek riskli hastaları tanımlamak için tahmini analitiği kullanmak, enfeksiyonları ve istenmeyen olayları azaltmak için kanıta dayalı protokoller uygulamak gibi kalite iyileştirmelerine imkan sağlaması açısından büyük veri dikkate alınabilir. ${ }^{16}$

\section{Hasta Katılımı ve Büyük Veri}

Kalite uygulamalarında hasta katılımı son derece önemlidir.36 Hastaların en iyi değeri veren bakım protokolünü veya rejimini belirlemelerine yardımcı olmak için tıbbi prosedürlerle ilgili verileri toplayarak ve yayınlayarak katılımcı sağlık hizmetlerinin desteklenmesi mümkün olabilir. Böylece bireysel sağlık girişimlerinin desteklenerek sonuçların iyileştirilmesi sağlanabilir. Bireysel sağlık girişimlerinin desteklenmesine ilişkin önemli çabalar vardır. Çoğu ödeyici, hastanın kendi bakımını yönetmesine, kendi sağlayıcılarını bulmasına ve sağlığını geliştirmesine yardımcı olan mobil uygulamaları geliştirip kullandığını belirtmektedir. ${ }^{27}$ Bu uygulamalardan biride "Talep Üzerine Analiz"dir (Analytics on Demand). Yeni bir analitik çözüm sunan Talep Üzerine Analiz, önceden oluşturulmuş gösterge tablolarını içerir, ihtiyaç duyulan klinik ve finansal verileri hızlı bir şekilde hastalara sunar. Böylece hem ayaktan hem de yatan hastalara poliklinik ya da servis gibi her türlü hastane ortamında hastaların anlık karar verme durumları için gerekli verileri hızlıca sunarak destek olur. Talep Metodolojisi Analizi, hizmet sağlayıcıların verileri doğru bir şekilde takip etmesini ve analiz etmesini sağlar. ${ }^{37}$

Ayrıca hasta ve yakınlarının hayal kırıklıklarının çoğunlukla nedeni, bu hizmet maliyetlerinin genelde şeffaf olmaması ve hizmet kalitesi ile ilişkilendirilmeden sağlayıcıların göreceli pazarlık gücüyle yürütülmesinden kaynaklanır. Aynı sağlık hizmetlerinin farklı maliyetlerle sunulması sıklıkla karşılaşılan bir durumdur. Örneğin, Büyük veri analizi ile hastalar, belirli prosedürler için en yüksek maliyeti yaratan doktorlar ve tedavilerle ilgili bilgilere erişebilecek; doktorlarda hangi testlerin gereksiz
Sakarya Tip Dergisi

2018;8(2):205-213 
Sakarya Tip Dergisi 2018;8(2):205-213 olduğunu daha iyi anlayabilecek, böylece her iki paydaşta maliyetleri görerek onları düşürmek için çalışabileceklerdir. ${ }^{38}$

\section{Verimlilik ve Büyük Veri}

Yüksek kaliteli bir sağlık sistemi, verimli bir bakım sağlamalıdır. Verimlilik en iyi değeri elde etmek üzere kaynakların kullanımıdır. ${ }^{22}$ Gerek temel maliyetler gerekse de sonuç verileri, kalite iyileştirmek ve maliyet azaltmak için birlikte analiz edilebilir ${ }^{38}$ Büyük veri ile öngörülen ve ileriye dönük gelişmiş analizler, genellikle risk altındaki hastalarla ilgili öngörülerde bulunmaya odaklanır. Örneğin, sağlayıcılara, hangi hastaların acil müdahale veya ek tedaviye ihtiyaç duyduklarını yada hangi hastaların belirli sağılılı yaşam programlarından en fazla fayda sağlayabileceğini belirlemelerine yardımcı olabilirler. ${ }^{17}$ Ayrıca büyük verinin, klinik işlem süreçleri yanı sıra sağlıkta birçok alanda kullanıldığında, israf ve verimsizliği azaltmaya yardımcı olabileceği belirtilmektedir. ${ }^{110,39-41}$ Çünkü büyük verinin, en iyi uygulamaların belirlenmesini ve sağlık hizmeti sunumunda tutarsızlıkların ortaya çıkmasını sağlayarak bakım kalitesini artırmaya ve aynı zamanda maliyetleri düşürmeye yardımcı olabileceği düşünülmektedir. Bu noktada, koroner hastalıkla mücadelede basit ve spesifik önlemlerin alınması konusunda (aspirin almak, kolesterol taramaları yapmak ve sigarayı bırakmak gibi) büyük veri kullanımı ile öneri sunmak suretiyle ABD'nin sağlık harcamalarını yıllık 30 milyar dolar azaltabileceği tahmin edilmiştir. ${ }^{38}$

Sağlık verilerini analiz etmek, modeller ve algoritmalar geliştirmek için keşif amaçlı halen devam eden birtakım girişimler vardır. Bunlardan biri olan "IMI2 - Daha İyi Sonuçlar İçin Büyük Veriler Programı"dır (The IMI2 Big Data for Better Outcomes (BD4BO) Programme). Bu program, gelişmekte olan birçok veri kaynağından gelen veri zenginliğinin sunduğu firsatlardan istifade ederek Avrupa'daki değer ve sonuç odaklı sürdürülebilir kaliteli bir sağık sistemi gelişimini kolaylaştırmayı ve desteklemeyi amaçlamaktadır. ${ }^{42}$

\section{Hasta Güvenliği ve Büyük Veri}

Hasta güvenliği geliştirme girişimleri, bir sağılık kuruluşunun kalite yönetimi çabasının önemli bileşenidir. ${ }^{23}$ Hasta güvenliği hastanın potansiyel sağılık tehlikesi yaratabilecek durumlardan korunması, verilen sağılık hizmetine bağlı olarak gelişebilecek hataların önlenmesi ve bu hataların neden olabileceği hasarların azaltılmasıdır. ${ }^{25,43}$ Sağlık hizmetlerinde kaliteye ulaşmak ve sürdürmek maksimum hasta güvenliği gerektirir. ${ }^{23,25}$ Hasta güvenliğini artırmak üzere, bir hastanın zarar görme olaslığını azaltmak ve bu konuda değişikliklerin gerekli olup olmadığını görmek için sistem ve süreçler incelenmelidir. Amaç, hata riskini azaltmaktır. ${ }^{23}$ Sağlık bakım kuruluşlarının teşvik edici önlemleri alması ve gelişebilecek tıbbi hatalara yönelik cezaları önlemesi için ihtiyaç duyulan klinik ve finansal verileri, büyük veri teknolojileri hızlı bir şekilde sunarak hastanın bakımını olumlu yönde etkilemekte ve büyük veri ile sunulan yeni analitik çözümler de kuruluşların değer temelli bakıma geçmelerine yardımcı olmaktadır. ${ }^{44}$ Hasta güvenliğini ihlal eden tıbbi hatalar ve kazalar, önemli bir ölüm kaynağı ya da uzun süreli sakatlık oluşturabilir. Dolayısıyla büyük veri ile kazaların nerede, ne zaman ve nasıl olacağı hakkında bilgi sağlama, sağlık stratejisinin önemli bir bileşenini oluşturmaktadır. ${ }^{38}$

Ayrıca büyük veri ile hastalık önleme girişimlerini desteklemek için geniş kapsamlı hastalık profillemesi yapmak da mümkün olabilir ki bu, kurumlara kaliteyi ve sonuçları iyileştirme fırsatını sunacaktır. $^{27}$ Büyük verilerin sentezlenmesi ve analiz edilmesiyle ilişkiler, modeller ve eğilimlerin ortaya çıkarılması sağlanır. Böylece daha ayrıntılı, daha kapsamlı ve daha doğru teşhis ve tedavilerin ge- 
liştirilmesi mümkün olabilir. Bunun sonucunda da daha düşük maliyetle ve genel olarak daha iyi sonuçlara erişerek daha güvenli ve kaliteli bakım sağlanabilir. ${ }^{10}$

Yapılandırılmış veya yapılandırılmamış olsun büyük verilerin analizi, genellikle önemli lojistik çabalar ve bilgi işlem gücü gerektirir. Büyük verilerin değer zinciri, veri üretme, toplama, depolama, işleme ve nihayetinde ilgili verilerin dağıtımı ve analizinden oluşur. Uygulamalar muhtemel veri takibi ya da retrospektif veri analizi olabilir. Bu analizler, kalitenin temel hedefleri olan aşağıdaki konularda önemli katkılar sağlayabilir: ${ }^{45,46}$

- Tedavilerin etkinliğini ve kalitesini arttırma:

- Erken tanı erken tedavi

- Illaç reaksiyon olasilığını azaltmak

- Tibbi hata azaltılması

- Nedenselliklerin belirlenmesi

- Eşlik eden hastalıkların anlaşılması

- Sağlık hizmeti sunucularının ve profesyonellerin hatta tüm sektör paydaşlarının arasındaki iletişim kanallarını geliştirme

- Sosyal ağlar, hastalık ağları veya tıp ağları gibi farkı ağların birleşmesiyle araştırma ağlarının yoğunlaştııılması

- Hastalıkların önlenmesi için toplumsal ve bireysel seviyelerde hastalık risk faktörlerinin belirlenmesine yönelik imkânların genişletilmesi

- Müdahalelerin etkinliğinin artıııması

- Doğrudan verilen bilgilere dayanılarak daha bilinçli tıbbi kararlar verme yeteneği sayesinde farmakovijilansın ve hasta güvenliğinin geliştirilmesi,

- Sonuçların tahmini, örneğin kronik hastalıklardan korunma ve iyileştirilmesi, risk haritaları, demografik eğilimlerin ve bağışıklıkların yanı sıra hastalık iletim yollarının daha iyi anlaşııası yoluyla küresel bulaşıcı hastalıkların takibi

- Bilgi paylaşma, örn. hekimlere, klinik uygulamaya rehberlik eden güncel kanıtlarla yardım edilmesi

- Maliyetlerin kontrolü ve iyileşmesiyle verimsizlik ve israfın azaltılması,

Yukarıda sıralanan büyük verinin sunduğu imkanlar, aynı zamanda kalite uygulamalarıyla erişilmek isten hedeflerdir. Çünkü hastaların teşhis ve tedavilerinin klinik açıdan kaliteli ve maliyet etkin yöntemlerinin belirlenmesi için yapılan karşılaştırmalı etkinlik araştırmalarında büyük veriyi kullanmak verimli ve etkin sonuçlar üretilebilir. Ayrıca büyük veri operasyonların verimliliğini ve kalitesini artırmak üzere klinik karar desteği sunar. Bunların yanı sıra büyük veri teknolojileri ile büyük miktarda veriyi eleme, anlama, kategorilere ayırma ve ondan öğrenme ve olası sonuçları tahmin etmekle bakım noktasında klinisyenlere ve hastalara alternatif tedaviler önermek mümkün olabilir. Yani tanı ve tedavi seçimini iyileştirmek, triyaj, iyatrojenik enfeksiyonlar, reçete kaynaklı hatalar ve diğer tıbbi hataları önlemek için hemşirelere ve doktorlara gerçek zamanlı bilgi sağlayabilir. Özellikle uzaktan hasta izleme ve proaktif bakımda yarar sağlayacak kişilerin belirlenmesi için tahmini analitik uygulamaların kullanımı söz konusudur. Böylece tıbbi verilerle ilgili şeffaflı̆ı̆ artırılması, uzaktan hasta izleme ve proaktif bakımın sunulmasına imkan sunar. Kişiselleştirilmiş bakım sunumunda destek sağlar. Hastalar için en iyi uygulamaları belirleyerek kişiselleştirilmiş bakımdan gerçek zamanlı yararlanılabilir. Bu çözümler, bir hastada hastalık semptomları gelişmeden önce erken teşhis ve tanı yapma imkanı sunar. Hastalı̆ı̆ daha derin ve geniş genomik karakterizasyonları ile hastalıktan
Sakarya Tıp Dergisi

2018;8(2):205-213

ALTINDiş

Sağllkta Kali

Büyük Veri 
Sakarya Tup Dergisi 2018;8(2):205-213 korunma ve başarılı tedavi rejimleri elde edilebilir. Temel performans göstergelerine ilişkin verilerin analiz edilmesiyle elde edilen sonuçlar, ilgili alandaki (Politik, finansal ve yönetim) karar vericileri destekleyebilir. ${ }^{10,12,39,47-49}$

\section{Sonuç}

Bilgi ve iletişim teknolojilerindeki gelişmelere bağı olarak önemi giderek artan büyük veri kavramı sağılık hizmetlerinde önemli bir yere sahiptir. Sağlığı korunması, geliştirilmesi, doğru tanı, teşhis ve tedavi yöntemlerinin uygulanabilmesi, tıbbi hataların azaltılması, hasta güvenliğinin iyileştirilmesi ve bakım kalitesinin artırılması gibi pek çok alanda istenen iyileşmeler için gerekli olan kaynak ve yöntem, büyük veri uygulamaları ile sağlanabilmektedir.

Sağlık hizmetlerinde büyük verinin ile sağlık kurum/kuruluşlarının eksiklikleri ve risklerinin belirlenmesi, üretilen sağlık çıktılarının geliştirilmesi, maliyetlerin azaltılması, çalışan-hasta ilişkilerinin geliştirilmesi ve hasta memnuniyetinin artışına yardım edeceği düşünülmektedir.

Günümüzde sadece ülkemizde değil dünyada artmaya devam eden ve önemli bir sorun haline gelen sağlık ihtiyaçlarının karşılanmasında yaşanan finansman sorununa olumlu katkılar sunacağı düşünülmektedir. Bu katkılar, değer temelli sağlık hizmetlerinin üretiminde, kıt kaynakların doğru kullanılmasına olanak sağlayan büyük veri uygulamaları ile elde edilebilir. Büyük verilerin sağlık hizmetlerinde uzun dönemde değer yaratma imkanı sunması açısından da önemli bir yere sahip olacağı öngörülmektedir.

Büyük verilerin kullanımında deneyimsizlik, analitik geliştirme maliyeti gibi bir takım zorlukların bulunmasına rağmen büyük veri teknolojilerinin benimsenmesi, uygulanması ve kullanılmasının, sağılık hizmetlerinde olumlu bir etkiye sahip olacağı düşünülmektedir. Bu anlamda sağık hizmeti sunan kurumlara, büyük veri analizi için gerekli kaynaklara (belirli teknoloji, analitik yöntemler vs) ve veri bütünleştirmesine yönelik yatııımlar yapmaları önerilmektedir. 
1. Manyika J, Chui M, Brown B, Buhin J, Dobbs R, Roxburgh C, Byers AH. Big Data: The Next Frontier for Innovation, Competition, and Productivity. USA: McKinsey Global Institute, 2011. file:///C:/Users/Uzman/Downloads/MGI_big_data_full_report.pdf (Erişim Tarihi: 22 Ekim 2017)

2. De Mauro A, Marco Greco M, Grimaldi M. What is Big Data? A Consensual Definition and a Review of Key Research Topics. International Conference on Integrated Information (IC-ININFO 2014) AIP Conf. Proc. 2015; 1644, 97-104. doi: 10.1063/1.4907823.

3. Khan N, Yaqoob I, Hashem IAT, et al. Big Data: Survey, Technologies, Opportunities, and Challenges. The Scientific World Journal 2014; 712826. http://doi.org/10.1155/2014/712826

4. Big Data Value Association BDV. Big Data Technologies in Healthcare Needs, opportunities and challenges. 2016. http://www.bdva.eu/sites/ default/files/Big\%20Data\%20Technologies\%20in\%20Healthcare.pdf (Erişim Tarihi 22 Kasım 2016).

5. OECD. Data-Driven Innovation: Big Data for Growth and Well-Being, OECD Publishing, Paris, 2015. http://dx.doi.org/10.1787/9789264229358-en

6. Olaranke I, Oluwaseun O. Big Data in Healthcare: Prospects, Challenges and Resolutions. FTC 2016 - Future Technologies Conference'2016. 6-7 December 2016. San Francisco, United States.

7. Harper E. Can big data transform electronic health records into learning health systems? Stud Health Technol Inform 2014; 201: 470-5.

8. Ehrenstein V, Nielsen H, Pedersen AB, Johnsen SP \& Pedersen L. Clinical epidemiology in the era of big data: new opportunities, familiar challenges. Clinical Epidemiology 2017; 9: 245-250.

9. Herland M, Khoshgoftaar TM, Wald R. A review of data mining using big data in health informatics. Journal Of Big Data 2014; 1; 2. https://doi. org/10.1186/2196-1115-1-2.

10. Raghupathi W, Raghupathi V. Big data analytics in healthcare: promise and potential. Health Information Science and Systems 2014; 2, 3. doi: $10.1186 / 2047-2501-2-3$

11. IHTT . Transforming Health Care through Big Data Strategies for leveraging big data in the health care industry. 2013. http:// c4fd63cb482ce6861463-http://c4fd63cb482ce6861463-bc6183f1c1 8e748a49b87a25911a0555.r93.cf2.rackcdn.com/iHT2_BigData_2013. pdf (Erişim Tarihi: 22 Ekim 2017)

12. Priyanka K, Kulennavar N. Survey On Big Data Analytics In Health Care. International journal of Computer Science and Information Technologies 2014; 5 (4): 5865-5868.

13. https://www.verywell.com/sources-of-big-data-in-health-care-1739184 (Erișim Tarihi: 4 Aralık 2017).

14. Salas-Vega S, Haimann A, Mossialos E. Big Data and Health Care: Challenges and Opportunities for Coordinated Policy Development in the EU. Health Systems \& Reform 2015; 1(4): 285-300.

15. National Quality Forum NQF. Data Needed for Systematically Improving Healthcare.2015. file:///C:/Users/Uzman/Downloads/data_for_systematic_improvement_final_white_paper.pdf (Erişim Tarihi: 12 Kasım 2017).

16. Bresnick J. Healthcare Big Data Analytics Plays Critical Role in Quality.2015. https://healthitanalytics.com/news/healthcare-big-dataanalytics-plays-critical-role-in-quality (Erișim Tarihi: 5 Kasım 2017)

17. IBM. Data-driven healthcare organizations use big data analytics for big gains. 2013. https://www-03.ibm.com/industries/ca/en/healthcare/ documents/Data_driven_healthcare_organizations_use_big_data_analytics_for_big gains.pdf (Erișim Tarihi: 12 Aralık 2017).

18. Er H. Toplam Kalite Yönetimi ve İnsan Kaynakları Ilişkisi, Beykent Üniversitesi Sosyal Bilimler Enstitüsü Işsletme Yönetimi Ana Bilim Dalı Yönetim Ve Organizasyon Bilim Dalı Yüksek Lisans Tezi, 2014, ístanbul.

19. Eraslan, N. İstanbul ilindeki Kamu Ve Özel Hastanelerde Kalite Yönetim Sisteminde Sürekli İyileştirmenin (Kaizen), İnsan Kaynakları Yönetimi Üzerine Etkileri. Okan Üniversitesi Sağlık Bilimleri Enstitüsü Sağıkta Kalite Yönetimi Anabilim Dalı Yüksek Lisans Tezi, 2014, ístanbul.

20. Erdemir A. Sağılk Hizmetlerinde Toplam Kalite Yönetimi, Beykent Üniversitesi Sosyal Bilimler Enstitüsü İşletme Yönetimi Anabilim Dalı Hastane Ve Sağlık Kurumları Yönetimi Bilim Dalı Yüksek Lisans Tezi, 2015, ìstanbul.

21. Institute of Medicine Report. Crossing the Quality Chasm: A New Health Care System for the 21st Century. Washington DC: National Academies Press, 2001.

22. Teleki SS, Damberg CL, Reville RT. Quality of Health Care:What Is It,Why Is It Important,and How can It Be Improved in California's Workers Compensation Programs? 2003. http://www.dir.ca.gov/chswc/caresearchcolloquium/p5/stephanieteleki.pdf (Erșim Tarihi: 22 Kasım 2017).

23. Spath P. Introduction Pat R I C E S Pat H Healthcare Quality Management To Introduction. Health Administration Press, 2009, Chicago, Illinois.

24. Narayanan A, Greco M, Powell H, Coleman L. The Reliability of Big "Patient Satisfaction" Data. Big Data 2013; 1(3):141-51.

25. Çavuş MF, Gemici E. Sağllk sektöründe toplam kalite yönetimi. Akademik Sosyal Araştırmalar Dergisi 2013; 1(1): 238-257.

26. Simpao F, Ahumada LM, Rehman MA. Big data and visual analytics in anaesthesia and health care. British Journal of Anaesthesia 2015; 115(3): 350-356.

27. Knowledgent White Paper Series. Knowledgent. Big Data and Healthcare Payers. 2014. https://knowledgent.com/wp-content/uploads/2014/07/Big-Data-and-Healthcare-Payers-Whitepaper.pdf (Erişim
Tarihi: 4 Kasım 2017)

28. PluraJ. Continual Improvement Within The Quality Management Systems. Kvalıta Inovácıa Prosperıta 2000;1: 13-22.

29. Morris C, Bailey K. Measuring Health Care Quality: An Overview of Quality Measures.2014. http://familiesusa.org/sites/default/files/product_documents/HSI\%20Quality\%20Measurement_Brief_final_web.pdf (Erișim Tarihi 19 Aralık 2017).

30. Mohebifar R, Hasani H, Barikani A, Rafiei S. Evaluating Service Quality from Patients' Perceptions: Application of Importance - performance Analysis Method. Osong Public Health Res Perspect 2016; 7(4): 233 238.

31. Backman C, Vanderloo S, Forste AJ. Measuring and improving quality in university hospitals in Canada: The Collaborative for Excellence in Healthcare Quality. Health Policy 2016; 120(9): 982-986.

32. Dennis, J.A. Using "big data" to improve health care services and rese arch. The Southwest Respiratory and Critical Care Chronicles, [S.I.], v. 4, n. 13, p. 49-51, jan. 2016. ISSN 2325-9205. Available at: <http:// pulmonarychronicles.com/index.php/pulmonarychronicles/article/ view/245/622>. (Erişim Tarihi: 10 Kasım 2017)

33. http://www.thiopconsulting.com/three-ways-use-big-data-healthcare/ (Erișim Tarihi: 2 Aralık 2017).

34. Rudin RS, Gidengil CA, Predmore Z, Schneider EC, Sorace J, Hornstein R. Identifying and Coordinating Care for Complex Patients: Findings from the Leading Edge of Analytics and Health Information Technology. Santa Monica, CA: RAND Corporation, 2016. https://www.rand.org/pubs/research_reports/RR1234.html. (Erişim Tarihi: 19 Aralık 2017)

35. AHRQ, Agency for Healthcare Research and Qualit. https://www.ahrq gov/professionals/quality-patient-safety/talkingquality/create/sixdomains.html. Erişim Tarihi: 22 Aralık 2017.

36. Longtin Y, Sax H, Leape LL, Sheridan SE, Donaldson L \& Pittet D. Patient Participation: Current Knowledge and Applicability to Patient Safety. Mayo Clinic Proceedings 2010; 85(1): 53-62. http://doi.org/10.4065/ mcp. 2009.0248

37. http://www.businesswire.com/news/home/20160215005311/en/ latric-Systems-Launches-Analytics-Demand\%E2\%84\%A2-GivingHealthcare (Erişim Tarihi: 16 Kasım 2017)

38. Pentland A, Reid TG, Heibeck T. Big data and health: revolutionizing medicine and public health. 2013. http://kit.mit.edu/sites/default/files/ documents/WISH_BigData_Report.pdf (Erişim Tarihi: 22 Kasım 2017)

39. Kumar H, Singh N. Review paper on Big Data in healthcare informatics. International Research Journal of Engineering and Technology 2017, 4(2): 197-201.

40. Etheredge LM. Rapid learning: A breakthrough agenda. Health Affairs 2014; 33(7): 1155-1162.

41. McKinsey Global Institute. Big data: The next frontier for innovation, competition, and productivity".2011. https://bigdatawg.nist.gov/pdf/ MGI_big_data_full_report.pdf (Erişim Tarihi: 15 Kasım 2017)

42. NICE (National Institute for Health and Care Excellence). Data Science for Health and Care Excellence: Harnessing the UK opportunities for new research and decision-making paradigms https://www.nice.org.uk/Me$\mathrm{dia} /$ Default/About/what-we-do/science-policy-and-research/getreal-ukdata-science-report.pdf (Erișim Tarihi: 8 Aralık 2017).

43. Yalçın, Ş, Acar, A. "II. Uluslararası Sağlıkta Performans ve Kalite Kongres Bildiriler Kitabı", (Ed. Harun Kırılmaz), T.C. Sağlık Bakanlığı Performan Yönetimi Kalite Geliștirme Daire Bașkanlığı, Cilt:1, 2010, Ankara.

44. Iatric Systems Launches Analytics On Demand ${ }^{\mathrm{TM}}$, Giving Healthcare Providers Timely Clinıcal Qualıty Data For Value-Based Care (2016). https:// chimecentral.org/iatric-systems-launches-analytics-demand-giving-healthcare-providers-timely-clinical-quality-data-value-based-care/ (Erişim Tarihi: 17 Aralık 2017)

45. Habl C, Renner AT, Bobek J, Laschkolnig A. Study on Big Data in Public Health, Telemedine and Healthcare Final Report (2016). https:// ec.europa.eu/health/sites/health/files/ehealth/docs/bigdata_report en.pdf (Erişim Tarihi: 22 Kasım 2016).

46. Stanford Medicine, Health Trends Report: Harnessing the Power of Data in Health, 2017. https://med.stanford.edu/content/dam/sm/sm-news/ documents/StanfordMedicineHealthTrendsWhitePaper2017.pdf (Erişim Tarihi: 17 Kasım 2017)

47. Feldman B, Martin EM, Skotnes T. Data in Healthcare Hype and Hope, 2012. http://www.kmhealthcare.net/images/hypeandhope.pdf (Erişim Tarihi: 22 Ekim 2017)

48. Krumholz HM. Big data and new knowledge in medicine: the thinking, training, and tools needed for a learning health system. Health Aff 2014; 33(7): 1163-1170

49. Reeder-Hayes KE, Troester MA, Meyer AM. Reducing Racial Disparities in Breast Cancer Care: The Role of 'Big Data' . Oncology Journal 2017; 31;10. http://www.cancernetwork.com/breast-cancer/reducing-racialdisparities-breast-cancer-care-role-big-data (Erişim Tarihi: 21 Kasım 2017) $\pi$
$D$
2
$z$
$D$
$\pi$
$D$
$D$

Sakarya Tıp Dergisi 2018;8(2):205-213

ALTiNDiş

Büyük Veri

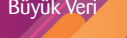

